TRABAJOS DE PREHISTORIA

54, n. $^{\circ} 2,1997$, pp. 29-42

\section{A REASSESSMENT OF THE STUDY OF CUT MARK PATTERNS TO INFER HOMINID MANIPULATION OF FLESHED CARCASSES AT THE FLK ZINJ 22 SITE, OLDUVAI GORGE, TANZANIA}

\author{
UNA NUEVA APRECIACIÓN \\ DEL ESTUDIO DE LOS PATRONES \\ DE MARCAS DE CORTE PARA INFERIR \\ MANIPULACIÓN HOMÍNIDA \\ DE CARCASAS CON CARNE EN EL \\ YACIMIENTO FLK ZINJ 22 DE OLDUVAI, \\ TANZANIA
}

MANUEL DOMÍNGUEZ-RODRIGO (*) sirven para inferir que los homínidos tuvieron un acceso primario a las carcasas representadas en el yacimiento FLK Zinj de Olduvai.

Key words: Cut marks. Hunting. Scavenging. Bone section. Limb Bones.

Palabras clave: Marcas de Corte. Caza. Carroñeo. Sección ósea. Huesos de las extremidades.

\section{INTRODUCTION}

For more than a century, the association of stone tools and bones at Paleolithic sites was interpreted as the result of hominids hunting animals and transporting them to their camps. Hunting was thus considered the trigger of the evolution of human behavior. It was only during the late 70's and early 80's that the first scavenging hypotheses appeared in the international paleoanthropological forum. Scavenging permitted on to reconstruct the process of human evolution from a more gradualistic standpoint than hunting: 
from a basically vegetarian diet (like that of most primates), hominids evolved into scavengers and then into hunters (thought of as a distinctive human behavior). Thus, in the beginning of this discussion, hominids were pictured as marginal scavengers with a minor participation in site formation (Binford, 1981). Later, when they were discovered to have played a major role in early archaeological sites, they were thought to have been secondary scavengers that obtained their food from other carnivores' kills (Blumenschine, 1986, $1988,1991,1995)$. The hypothetical use of scavenging as a strategy for obtaining food allowed mechanisms and factors other than hunting to be considered as crucial in human evolution. Ethological models were used to account for hominid behavior, and the "modern human hunter-gatherer" model was pushed forward in time, since it was judged inappropriate to account for early human behavior about 2 million years ago. However, all this modeling still is highly speculative and the discarding of the "modern human" model -in a structural sense-may be premature.

The discussion of hominid behavior at East African Plio-Pleistocene sites is still a controversial issue. After the recognition that hominids were the main agents responsible for bone transport and modification at sites and that other scavengers, namely hyenas, processed and depleted the remains abandoned by them (Bunn, 1982, 1991; Bunn \& Kroll, 1986, 1988; Bunn \& Ezzo, 1993; Potts, 1982, 1988; Blumenschine, 1988, 1991; Blumenschine \& Bunn, 1987; Blumenschine \& Marean, 1993; Selvaggio, 1994; Capaldo, 1995), the current debate is focussed on the order of access that hominids had to such carcasses. The hunting-versus scavenging discussion is still highly speculative on both sides, for we have not been able to discern the main products that hominids were obtaining from animals yet. Oddly enough, there seems to be a tendency of debating this question from its extremes. Those who argue that hominids had a primary access to carcasses believe that hunting was an important behavior in their adaptive patterns (Bunn, 1981, 1982, 1983; Bunn \& Kroll, 1986; Bunn \& Ezzo, 1993; Oliver, 1994), whereas those researchers who support the scavenging hypothesis argue that hominids had a secondary access to remains and that they were mainly aiming at exploiting marrow from long bones and brain from heads (Blumenschine, 1991, 1995; Blumenschine \& Madrigal, 1993; Capaldo,
1995; Selvaggio, 1994). Nonetheless, there are some other plausible scenarios in between that have not received proper experimental attention so far. We are still in the first stage of research, and this means that, until we can devise the necessary testing methods to screen the information we have drawn from the archaeological record and ascertain (with a high degree of confidence) what products were exploited by hominids from carcasses, we will not be able to discuss whether these animals were hunted or scavenged.

Traditionally, this question has been approached by using comparative analyses of skeletal part frequencies and mortality profiles. However, the low resolution of these techniques is revealed by the fact that the same results are used by different researchers to support opposite views. Some of them suggest that carcasses were not defleshed when hominids had access to them (Bunn, 1982; Bunn \& Kroll, 1986; Bunn \& Ezzo, 1993; Potts, 1982, 1988), whereas others, based on the same data, indicate that hominids selectively broke those bones with higher energy yields from marrow (Blumenschine, 1991; Blumenschine \& Madrigal, 1993). However, skeletal element representation at sites is known to be dependent not only on hominid behaviour, but on other pre- and post-depositional processes. Ravaging by carnivores is one of the major processes responsible for biasing the archaeological record, by destroying and deleting axial elements and limb-bone ends (Marean et alii, 1992; Capaldo, 1995). Thus, it is not surprising that scavenging by hyaenas has been documented at some early sites, especially through the analysis of bone type frequency, of long bone epiphysis/shaft fragment ratios and the incidence of tooth-marks, and of the different bone sections where these marks appear (Blumenschine, 1988; Blumenschine \& Marean, 1993; Marean et alii, 1992). We must bear in mind that the original bone accumulation made by hominids at sites has been disturbed in such a way that it is difficult to know the state of carcasses prior to their final consumption (Capaldo, 1995).

Therefore, skeletal part profiles are not enough to know the stage of the consumption process in which carcasses were obtained before they were carried to sites. Studies of bone breakage patterns and the percussion marks on bone surfaces (Blumenschine \& Selvaggio, 1988) suggest that hominids were responsible for breaking most of the bones to gain access to the marrow they contained. 
But this simply demonstrates the last stage of hominid intervention in carcass processing. The question still remains whether it was also the only processing activity carried out by them at sites. Were bones selectively broken when their meat yields had been extracted or were they transported in a rather defleshed condition?

One of the main arguments used by some authors to support the first option is the abundance of cut marks on the surface of some bones at early sites. This is best expressed in Bunn \& Ezzo's (1993: 383) words:

"... because of the abundant defleshing cut marks on the elements that are comparable in location, orientation and frequency to defleshing cut marks on younger archaeological and ethnoarchaeological bones, where access to meat is not in doubt, the dominant, overall pattern indicated at FLK Zinj is active, probably confrontational scavenging, with at least some opportunistic hunting. It is simply unlikely that hominids would have consistently had access through passive scavenging to the limb elements that are best represented at FLK Zinj. Moreover, it is unlikely that these same elements would exhibit the documented patterns of defleshing cut marks if carnivores, feeding as primary predators or scavengers, had already consumed much, if any, of the proximal limb meat".

Nonetheless, others believe that this relation between cut marks and meat processing ac-tivities is an untested assumption that still has to be demonstrated. As Blumenschine (1991: 216) puts it: "... there are no experimental or ethnographic models that permit one to equate the proportion of parts that bear cut marks with the proportion of bones that were actually defleshed or disarticulated. Further, we do not know how to distinguish cut-marking produced while defleshing whole muscle masses from that inflicted during the removal of scraps of flesh that commonly survive carnivore consumption...".

Therefore, the mere presence of cut marks on fossil bone surfaces may seem to be no guarantee of hominids processing large amounts of flesh either. But in this case, and contrary to the skeletal part frequency, it is not due to the disturbance of other agents, but to the lack of referential frameworks, as Blumenschine rightly points out.

Due to the lack of reference for both hypothe- ses, cut mark frequencies on fossil bones were until recently of limited value for assessing the extent to which hominids processed fleshed carcasses or simply largely defleshed bones. Bunn \& Kroll (1986) suggested that cut mark patterns reflected the availability of flesh on bones and its extraction. This assumed, the variation in the percentages of cut marks should be the result of the differential distribution of muscle masses. However, Binford $(1981,1988)$ argued that cut mark percentages only reflect the frequency of contact of stone tools on bone surfaces and no relation with flesh extraction was necessary to account for them. Thus, he even claimed that they could be the result of removing the periostium from bones before they were broken. Following a similar assumption, Blumenschine $(1991,1995)$ argues that they could be due to the removal of the scraps of flesh that commonly survive carnivore consumption of carcasses. This would propitiate an immediate and frequent contact of stone tools and bone surfaces with their corresponding cut marking.

In order to shed more light to these opposing interpretations, since 1993 I have been conducting several studies in East Africa on cut mark patterns, modeling both processes: a primary access to fully fleshed carcasses and a secondary one, following felids and manipulating their defleshed kills. In the first of them (henceforth named Hypothesis 1) I used dual-patterned experiments -first humans, then scavengers (the so-called "hominid-tocarnivore" model by Blumenschine [1988, 1995]) - and in the second case (Hypothesis 2), I used three-patterned experiments, modeling a primary access of felids to carcasses, followed by humans and, eventually, other scavengers -"carnivore-to-hominid-to-carnivore" model (Blumenschine, 1988, 1995; Selvaggio, 1994).

Bearing in mind that middle-sized carcasses -that is size 3 (Bunn, 1982) animals-are predominant at Plio-Pleistocene sites, I focussed my study mainly on that size range. In a preliminary study to document anatomical distribution of cut marks on bones from carcasses obtained at felid kills, I realized they ocurred in regular patterns on the different bone types and bone sections (first stage of research) (Domínguez-Rodrigo, 1996). However, even though such a study demonstrated the short range of variation in homogeneous cases -that is, taking into account the same trophic dynamics and number of predators feeding on the same animal- 
of carcasses initially processed by lions, it was not suitable for establishing direct comparison with Plio-Pleistocene sites, since the analysis only focussed on the anatomical distribution of cut marks due to defleshing (first stage of research).

Then, a series of carcasses were used for modeling both hypotheses (primary and secondary access by hominids) in which meat removal and marrow extraction were carried out, followed by carnivore post-ravaging and deletion of remains (second stage of research) (Dominguez-Rodrigo, in press). In that study, it was shown how clearly patterned primary access to carcasses was and its range of variation. It was also shown that secondary access to carcasses resulted in a reverse pattern (negatively symmetrical) to that observed in primary access. When both referential frameworks were compared to the data drawn from the FLK Zinj site of Olduvai (Tanzania), the cut marked pattern of large mammals from this site showed a very similar distribution to that displayed by the primary access experiments (Domínguez-Rodrigo, in press). This is a clear indication that hominids were manipulating fleshed carcasses.

There was, nonetheless, a problem. The sample for secondary access was too small to obtain confidently its range of variation. Thus, the question of the possible extent of overlap between the degrees of variation of both samples could not be properly addressed. Furthermore, as I had tried to study variation in carnivore behavior in different ecological circumstances with diverse degrees of competition, half of the sample was obtained in Maasai Mara (Kenya) and the other half in Galana and Kulalu (Kenya); carcasses from the two areas being subjected differentially to distinct processes that should not be lumped together into the same sample. The reason for choosing these areas is that lion behavior concerning carcass processing is different in the two zones. In Maasai Mara the open grass plains and the faunal distribution therein force lions to live in large prides (of more than five individuals) (Domínguez-Rodrigo, 1996). In Galana and Kulalu, the landscape and the ecological situation are different from those of Maasai Mara. These areas are semi-arid steppes with plenty of bush land. Herbivores are thus scarcer and more scattered than in the Maasai Mara savanna ecosystem. These particular trophic dynamics account for the differential adaptive strategies of carnivores: they live in small num- bers. This situation was observed both among lions and hyenas. In both instances, the maximum number of individuals of the same species observed hunting or scavenging together was three. Solitary individuals were frequent. This type of carnivore adaptation seems to be a common adaptive pattern in this kind of ecosystem, as an adjustment to a dispersed prey assemblage and limited availability of water (Tilson \& Henschel, 1986). With a mean number of two lions processing each carcass, obviously the amount of meat from limb bones of carcasses was greater than that obtained in contexts, such as Maasai Mara, where the number of individuals that feed on the same animal is higher.

The different processes (carcasses processed by prides of lions in Maasai Mara and by solitary or a few (2/3) individuals in Galana \& Kulalu) required caution not to use both of them in the same model. Furthermore, using cow carcasses -as I did in Galana \& Kulalu- seems to yield a somewhat distorted result, since I have observed that in this ecosystem lions deflesh game carcasses more thouroughly (irrespective of the number of consumers) whereas they leave significant amounts of flesh when they hunt cows. This is due to the fact that they obtain them from human settlements and, after dragging them to a safer place, consume as much flesh as possible quickly and then leave because of fear of humans, who often try to chase them. Therefore, the cows that I used in my previous study (Domínguez-Rodrigo, in press) are useful to observe cut mark frequency variation according to flesh availability, but do not show typical processing patterns by lions. In addition, if we take into account that lions are usually gregarious predators organized in prides, the solitary pattern observed in Galana \& Kulalu does not seem to be appropriate. Further studies will nonetheless be carried out in this ecosystem to elaborate a comparative framework.

Thus, in the third stage of research (presented in this paper) in July 1996 two more carcasses from Maasai Mara were added to broaden the three-patterned experiment sample.

In this work, I intend to compare both samples (access to fleshed [Hypothesis 1] or defleshed carcasses (Hypothesis 2]) and discuss, first, if overlap exists and, if it does, evaluate what it means and how it can be used to interpret the cut mark patterns observed on the fossil bones of the large mammals of FLK Zinj site.

T. P., 54, n. ${ }^{\circ} 2,1997$ 


\section{METHODS AND SAMPLE}

The study was carried out during the summers of 1993 to 1996, in four successive field seasons, in the reserves of Galana \& Kulalu (southeast Kenya) and in the northern area of the Masai Mara National Reserve, in a broad zone situated between the Mara and the Olchorro le Musiara rivers in the south (and part of the territory between the latter and Olare Orok river) and the Mara river and the highlands in the north (Fig. 1). All the carcasses analyzed in three-patterned experiments were observed to have been hunted by lions or were spotted in the moment they were being processed by them. No other agent (e.g., vultures) intervened afterwards.

A total of 11 experiments make up the sample of this study. More than 300 long bones from 27 carcasses were originally included therein. Middle-sized carcasses (wildebeest, zebras, cows) were the aim of the research. The number of bones in each experiment was variable, but in all the experiments trying to test the complete process (dual-patterned and three-patterned models) the average number was of 12 long bones (Domínguez-Rodrigo, in press). Capaldo's (1995) study on carnivore depletion of bone remains shows that hyena post-ravaging varied according to the availability of bones. Thus, in some aspects, experiments made with few bones -sets of $1 / 3$ bones (Selvaggio, 1994)- are of doubtful value to make sustainable inferences and interpretations.

Control of the experiments was tight. In dualpatterned (hominid-to-carnivores) experiments, complete carcasses were butchered with stone tools and bones were broken to extract the marrow. Bone fragments were then ravaged by scavengers. In three-patterned experiments, fresh carcasses were obtained from lion kills, the remaining scraps of flesh were removed and then the procedure followed was the same as in dualpatterned experiments.

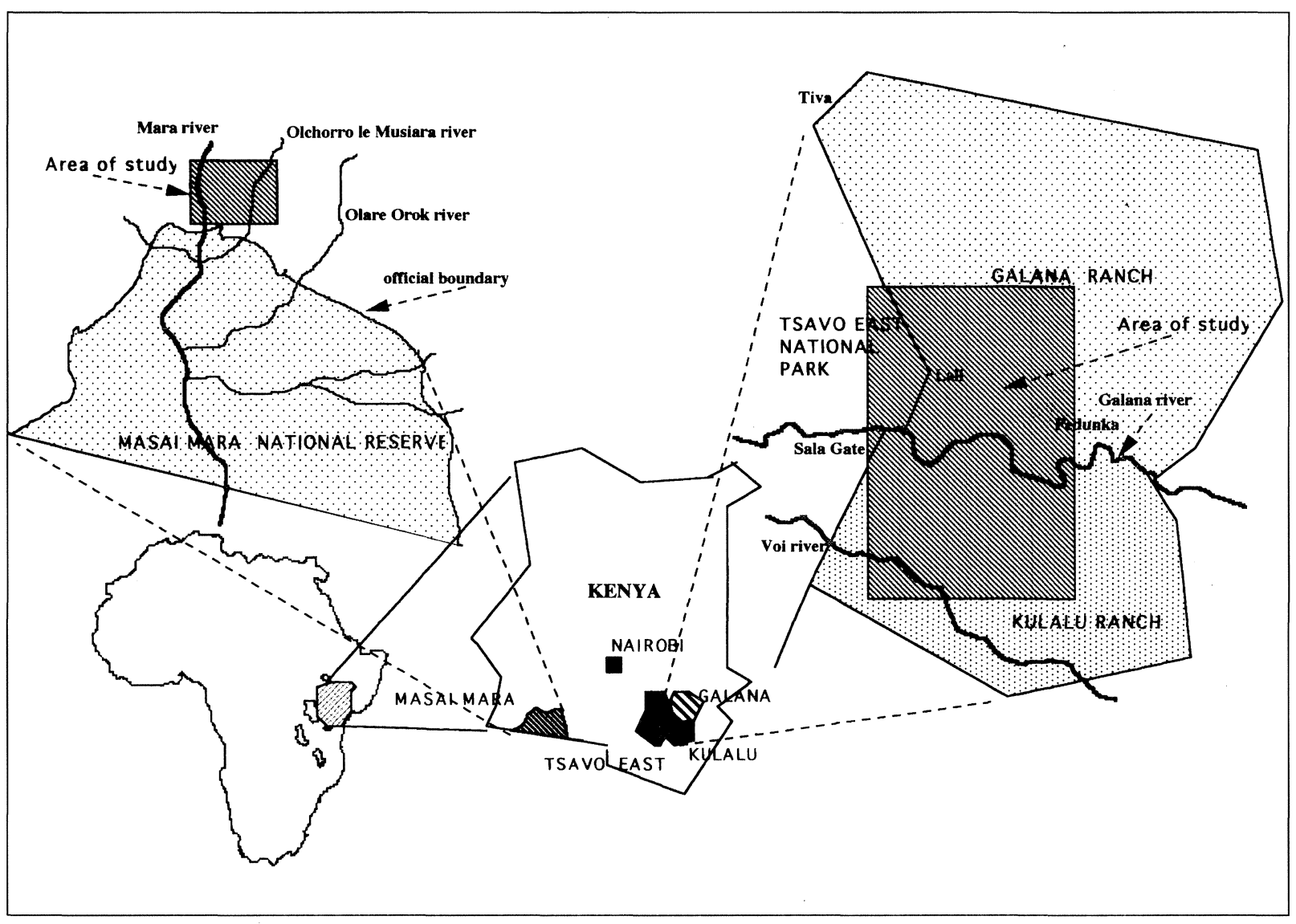

Fig. 1. Map of the areas where the study was carried out. 
Bearing in mind that the degree of experience of the butcher and the intentions of the researcher may influence the total distribution and percentages of cut marks (Haynes, 1991; Domínguez-Rodrigo, 1996) -e.g., paradoxically, Selvaggio's (1994) cut mark frequencies on defleshed bones were higher than those obtained by Capaldo's (1995) on fleshed carcasses-, I involved local people (Maasai and Mwalangulu) in the butchery of carcasses in all the complete sequence experiments, to avoid such a bias. Since only cut-mark patterns for meat removal and defleshing were sought, and not for carcass dismembering or disarticulation, I proceeded in most of the experiments to remove the flesh with the aid of lithic tools (simple flakes) and after butchery, bones were carefully disarticulated and separated into elements by using metal knives on the joints of the epiphyses in a controlled way. The cut marks thus created were not counted nor included in this study. They were easily distinguished from the rest by their location and internal morphology (observed microscopically with lenses). I also used stone tools (anvils, choppers and hammerstones) for breaking bones. Bones were placed either horizontally on the anvil or leaning on its lateral side-according to the occasion and the type of anvil- and a few blows at the midshafts were enough to expose the marrow cavities. Sometimes, I observed that when the bone was fractured by the first blow but not broken, additional blows were inflicted on the metadiaphyses and, if necessary, back again on the mid-shaft, alternating the points. Once bones were open, I extracted the marrow, without separating the flakes and fragments that remained together, due to the periostium. This accounts for the loss of information in experiments in which scavengers were involved, as epiphyses removal and disappearance also included the loss of the adhered fragments.

After each experiment was performed, I cleaned the bones by boiling them in a solution of water and neutral detergent and then each bone was then carefully examined both macroscopically and with binocular lenses (20X-80X), so as to be sure of the identification of marks. Marks were quantified and classified to specimen number, bone type, and bone section, in order to evaluate the total percentages of NISP with cut marks and their anatomical distribution. A formal division of bones into proximal/distal shafts and mid-shafts was made, to observe how meat removal was re- flected on the different bone sections. Limbs were also divided into three parts: upper (humerus \& femur), intermediate (radius \& tibia), and lower (metapodials).

In order to test the aforementioned hypotheses, I previously divided the experiments into different stages. Concerning the first hypothesis -the dual-patterned model (early access to carcasses by hominids, followed by hyenas)- I proceeded to butcher a carcass and then limb bones were broken to extract the marrow. Cut-mark representation-Hypothesis 1: Stage 1 (H1S1)-was then analyzed. Then, I butchered and broke the limb bones from another carcass and exposed them to the ravaging process of scavenging carnivores -Hypothesis 1: Stage 1/2 (H1S1/2a)-. For further complementary comparative background, I also used the information from the excavation of a temporary camp site of Ndorobo (Maasai) herd' ers, in which a cow had been butchered and consumed and exposed to carnivores (H1S1/2b), and that from a poachers' site in which several small bovids had been processed and consumed (H1S1/ 2c). As further comparative background to the defleshing and removal of scraps of meat from carcasses, I carried out another experiment (H1S1/ 2d) with the four complete legs of an dead adult wildebeest, which a Maasai assistant located for me in a small swampy area close to the Mara river, outside the official boundaries of the reserve (Fig. 1). Basalt flakes were used to butcher the carcass. After defleshing and demarrowing the bones, they were exposed to scavengers.

With respect to the second hypothesis -hominid access to carcasses after lions and before hyenas and jackals (the three-patterned model)- I started analysing cut-mark frequencies and distribution according to bone section (proximal/distal ends and mid-shafts) on nearly defleshed carcasses from lion kills (Domínguez-Rodrigo, 1996) -Hypothesis 2: Stage 1 (H2S1/2a)-. Then following the same steps with another carcass, I proceeded by breaking the bones to take out marrow, so as to see the representation of cut marks at this state of bone modification -Hypothesis 2: Stage 1/2 (H2S1/2b)-. Finally, I followed the same procedure with other carcasses, whose remains were eventually exposed to the action of carnivore scavengers -Hypothesis 2: Stage 1/2/3 (H2S1/2/3a \&b)-. In these three-patterned experiments, lions were observed initially feeding on all the carcasses and no other agent (e.g., vultures) intervened

T. P., 54, n. ${ }^{\circ} 2,1997$ 
before I took the bones.

For further details, see a description of each of the experiments in Domínguez-Rodrigo (in press). With the intention of increasing the number of three-patterned experiments, in 1996 two more carcasses from Maasai Mara were added to the sample (H2S1/2/3c\&d). They were two adult wildebeest processed by lions. $\mathrm{H} 2 \mathrm{~S} 1 / 2 / 3 \mathrm{c}$ was consumed by 8 individuals and $\mathrm{H} 2 \mathrm{~S} 1 / 2 / 3 \mathrm{~d}$ was processed by 13 individuals. The remaining scraps of flesh were removed with quartz and basalt flakes and bones were broken with hammerstones. Then, they were exposed to the action of scavengers.

\section{RESULTS}

The results obtained in the experiments simulating access to fully fleshed carcasses were the following (Tables $1 \& 2$ ):

1. A high percentage of cut-marked bones with respect to NISP (Number of Identified Specimens). In unaltered bone accumulations made by humans (H1S1: butchery plus bone breakage, without exposure to scavengers), the mean representation of cut-marked specimens is $57,5 \%$, which is fairly coincident with assemblages where carnivores have ravaged bones differentially: Ndorobo Boma (54\%), experiment with a cow $(55 \%)$ and bone accumulation at poachers'site (42\%). The only exception is observed in the H1S1d experiment (defleshing of a wildebeest) in which cut-marked specimens make up only $29 \%$ of the sample. This may be due to the fact that in this experiment only defleshing with stone tools was performed. The other process, the removal of the scraps of meat seems, therefore, to have a determinant influence on the high percentages of cut-marked specimens in the assemblages belonging to the Hypothesis 1 experiments. Thus, the range of variation of the representation of cutmarked specimens can be confidently situated on the interval of $30 \%-60 \%$.

2. Differential occurrence of cut-mark patterns. The meatiest elements (upper limb bones) are the highest ranked, with a mean percentage among the five types of studies -H1S1, H1S1/2a, H1S $1 / 2 b, H 1 S 1 / 2 c$ \& H1S1/2d- of about $60 \%$ of the total number of cut-marked bones. Intermediate bones are also highly cut marked, with a mean close to $30 \%$, and finally lower limb bones are scarcely cut marked (less than $10 \%$ ).
3. Differential distribution of cut marks according to bone section. In the pre-ravaged human-made accumulations (H1S1) the mean figure of cut-marked specimens from mid-shafts (with respect to the total number of all cut-marked fragments) is about $43 \%$. In post-ravaged assemblages, it becomes higher than $50 \%: \mathrm{H} 1 \mathrm{~S} 1 / 2 \mathrm{~b}(53 \%)$, $\mathrm{H} 1 \mathrm{~S} 1 / 2 \mathrm{c}(53 \%), \mathrm{H} 1 \mathrm{~S} 1 / 2 \mathrm{a}(54,5 \%)$ and $\mathrm{H} 1 \mathrm{~S} 1 / 2 \mathrm{~d}$ (70\%). This is due to the disappearance of some proximal/distal ends by density-mediated factors. Therefore, mid-shafts are the most abundant cutmarked specimens in bone assemblages that have completed the dual-patterned process.

In clear contrast, the situation observed in the experiments dealing with Hypothesis 2 are significantly different. The results are as follows:

1. A low percentage of cut-marked bones with respect to NISP. In the bone assemblage from the experiment with the cow in which flesh was abundant and bones were not exposed to scavengers $(\mathrm{H} 2 \mathrm{~S} 1 / 2 \mathrm{~b})$, the mean percentage obtained was $28,5 \%$. In the 2-3-patterned complete experiments the total percentage is $12,2 \%$ : $7 \%$ in $\mathrm{H} 2 \mathrm{~S} 1 / 2 / 3 \mathrm{a}$ and $19,5 \%$ in $\mathrm{H} 2 \mathrm{~S} 1 / 2 / 3 \mathrm{~b}$ (with more remains of meat available), $11,4 \%$ in $\mathrm{H} 2 \mathrm{~S} 1 / 2 / 3 \mathrm{c}$ and $10,5 \%$ in $\mathrm{H} 2 \mathrm{~S} 1 / 2 / 3 \mathrm{~d}$.

2. Differential occurrence of cut-mark patterns. Contrary to the Hypothesis 1 experiments, the meatiest limb elements (humerus and femur) are the lowest ranked. The mean percentage is $7,2 \%$ (increased by the presence of significant amounts of flesh from the two cows subjected to experimentation in Kulalu). The wildebeest carcasses from Maasai Mara yielded $0 \%(\mathrm{H} 2 \mathrm{~S} 1 / 2 /$ $3 \mathrm{a}), 8,6 \%(\mathrm{H} 2 \mathrm{~S} 1 / 2 / 3 \mathrm{c})$ and $3,7 \%(\mathrm{H} 2 \mathrm{~S} 1 / 2 / 3 \mathrm{~d})$ respectively, whereas both experiments in Kulalu yielded a somewhat higher representation: $16,5 \%$ $(\mathrm{H} 2 \mathrm{~S} 1 / 2 \mathrm{~b})$ and 7,6 \% (H2S1/2/3b). In a coniext of high stress on carcass processing such as Maasai Mara -that is, when the number of consumers is high- intermediate bones are also low-ranked (mean $=10,5 \%)$. Metapodials were the highest ranked elements $(>60 \%)$. In settings where the number of predators does not exceed 2-3 and complete consumption is delayed, the representation on these bones is higher (mean $=30,5 \%$ ) due to the presence of larger amounts of flesh: radius $(15 \%)$ and tibia $(46 \%)$. Therefore, cut-marked specimens from intermediate and lower bones are more abundant than those from upper limb bones.

3. Differential distribution of cut marks according to bone section. In highly flesh-depleted 


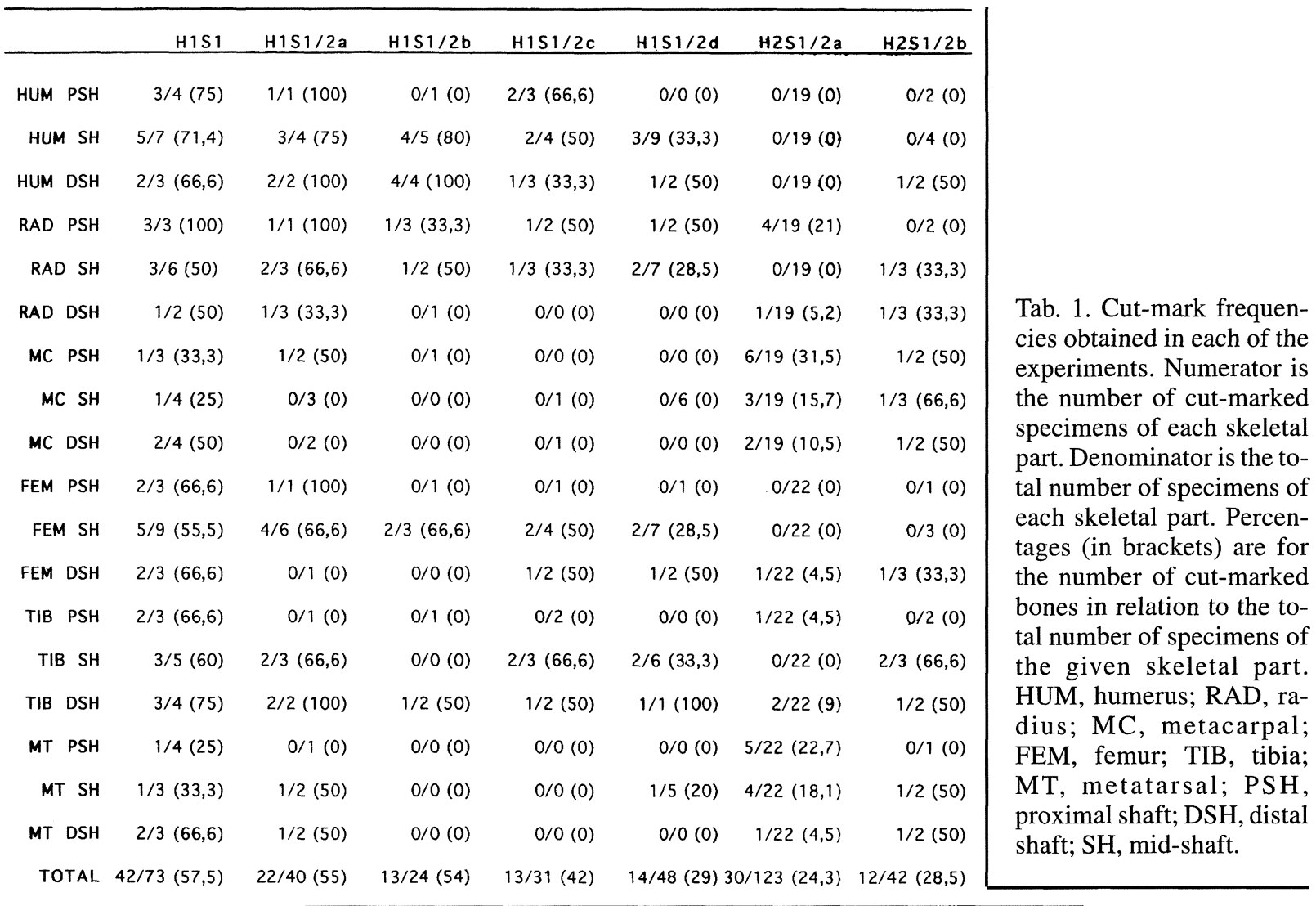

H2S1/2/3a H2S1/2/3b H2S1/2/3C H2S1/2/3d FLK Zinj (s) FLK Zinj (S) FLK Zinj (1) FLK Zinj (L)

\begin{tabular}{|c|c|c|c|c|c|c|c|c|}
\hline HUM PSH & $0 / 1(0)$ & $0 / 3(0)$ & $0 / 2(0)$ & $0 / 0(0)$ & $0 / 4(0)$ & $0 / 4(0)$ & $1 / 3(33,3)$ & $2 / 3(66,6)$ \\
\hline HUM SH & $0 / 7(0)$ & $0 / 9(0)$ & $0 / 4(0)$ & $0 / 5(0)$ & $8 / 45(17,8)$ & $14 / 45(31,1)$ & $3 / 13(23,1)$ & $4 / 13(30,7)$ \\
\hline HUM DSH & $0 / 4(0)$ & $0 / 5(0)$ & $1 / 4(25)$ & $0 / 3(0)$ & $6 / 17(35,3)$ & $7 / 17(41,1)$ & $4 / 6(66,7)$ & $5 / 6(83,3)$ \\
\hline RAD PSH & $1 / 5(20)$ & $1 / 4(25)$ & $1 / 3(33,3)$ & $0 / 2(0)$ & $3 / 15(20)$ & $6 / 15(40)$ & $2 / 4(50)$ & $3 / 4(75)$ \\
\hline RAD SH & $0 / 5(0)$ & $1 / 6(16,6)$ & $0 / 4(0)$ & $0 / 3(0)$ & $10 / 45(22,2)$ & $11 / 45(24,4)$ & $3 / 12(25)$ & $3 / 12(25)$ \\
\hline RAD DSH & $0 / 3(0)$ & $1 / 3(33,3)$ & $1 / 3(33,3)$ & $1 / 4(25)$ & $1 / 6(16,7)$ & $1 / 6(16,7)$ & $0 / 3(0)$ & $0 / 3(0)$ \\
\hline MC PSH & $1 / 2(50)$ & $1 / 3(33,3)$ & $1 / 2(50)$ & $0 / 3(0)$ & $2 / 10(20)$ & $3 / 10(33,3)$ & $2 / 6(33,3)$ & $2 / 6(33,3)$ \\
\hline MC SH & $0 / 3(0)$ & $1 / 4(25)$ & $0 / 3(0)$ & $1 / 3(33,3)$ & $1 / 20(5)$ & $1 / 20(5)$ & $1 / 12(8,3)$ & $1 / 12(8,3)$ \\
\hline MC DSH & $0 / 1(0)$ & $0 / 2(0)$ & $0 / 2(0)$ & $1 / 2(50)$ & $0 / 2(0)$ & $0 / 2(0)$ & $0 / 3(0)$ & $0 / 3(0)$ \\
\hline FEM PSH & $0 / 3(0)$ & $0 / 2(0)$ & $0 / 3(0)$ & $0 / 4(0)$ & $1 / 6(16,7)$ & $1 / 6(16,7)$ & $0 / 1(0)$ & $0 / 1(0)$ \\
\hline FEM SH & $0 / 10(0)$ & $0 / 6(0)$ & $0 / 6(0)$ & $0 / 5(0)$ & $7 / 41(17,1)$ & $10 / 41(24,3)$ & $2 / 17(11,8)$ & $5 / 17(29,4)$ \\
\hline FEM DSH & $0 / 4(0)$ & $1 / 3(33,3)$ & $1 / 4(25)$ & $1 / 5(20)$ & $0 / 5(0)$ & $0 / 5(0)$ & $1 / 2(50)$ & $1 / 2(50)$ \\
\hline TIB PSH & $0 / 2(0)$ & $0 / 1(0)$ & $0 / 3(0)$ & $1 / 3(33,3)$ & $0 / 1(0)$ & $0 / 1(0)$ & $2 / 9(22,2)$ & $3 / 9(33,3)$ \\
\hline TIB SH & $0 / 5(0)$ & $3 / 6(50)$ & $0 / 4(0)$ & $0 / 4(0)$ & $7 / 92(7,6)$ & $13 / 92(14,1)$ & $11 / 36(30,6)$ & $16 / 36(44,4)$ \\
\hline TIB DSH & $1 / 5(20)$ & $3 / 4(75)$ & $17 \%(20)$ & $0 / 4(0)$ & $2 / 7(28,6)$ & $2 / 7(28,6)$ & $2 / 3(66,7)$ & $2 / 3(66,7)$ \\
\hline MT PSH & $0 / 1(0)$ & $0 / 1(0)$ & $0 / 3(0)$ & $0 / 3(0)$ & $0 / 6(0)$ & $1 / 6(16,6)$ & $2 / 12(16,7)$ & $2 / 12(16,7)$ \\
\hline MT SH & $1 / 4(25)$ & $0 / 3(0)$ & $1 / 4(25)$ & $1 / 2(50)$ & $2 / 13(15)$ & $3 / 13(23)$ & $1 / 15(6,7)$ & $2 / 15(13,3)$ \\
\hline MT DSH & $1 / 2(50)$ & $1 / 1(100)$ & $0 / 2(0)$ & $0 / 2(0)$ & $1 / 4(25)$ & $2 / 4(50)$ & $0 / 2(0)$ & $0 / 2(0)$ \\
\hline TOTAL & $5 / 67(7)$ & $13 / 66(19,5)$ & $7 / 61(11,4)$ & $6 / 57(10,5)$ & $51 / 339(15)$ & $73 / 339(21,5)$ & $37 / 159(23,2)$ & $51 / 159(32)$ \\
\hline
\end{tabular}

T. P., 54, n. ${ }^{\circ} 2,1997$ 
carcasses (H2S1/2/3a, c \& d), with the exception of metapodials, no upper or intermediate limb bone exhibits any cut mark on the mid-shafts. In carcasses such as those from Kulalu, in which meat was still abundant, this percentage is higher ( $25 \%$ in $\mathrm{H} 2 \mathrm{~S} 1 / 2 \mathrm{~b}$ and $31 \%$ in $\mathrm{H} 2 \mathrm{~S} 1 / 2 / 3 \mathrm{a}$, without counting metapodial mid-shafts). Therefore, proximal/distal ends and not mid-shafts exhibit the highest occurrence of cut marks (mean > $80 \%$, except metapodials).

The differential distribution and percentages of cut-marked specimens between both sets of experiments in Maasai Mara and Kulalu is explained by the differential availability of meat in both of them (see Domínguez-Rodrigo, in press).

\section{DISCUSSION}

The frequency of cut marks observed in the FLK Zinj site apparently shows a unique pattern, although it bears a close resemblance with that exhibited by the Hypothesis 1 experiments (Tables 1 $\& 2$ ). If we interpret them from the above-mentioned criteria, the mean percentage of cut-marked bones with respect to NISP is $15 \%$ in smaller mammals and $23 \%$ in larger animals. These figures are lower than those obtained in most of the experiments trying to test Hypothesis 1 (however, they are also very close to the percentages observed in the experiment H1S1/2d, which shows a mean ratio of $29 \%$ of cut-marked specimens with respect to the total number of identified specimens) and match those achieved in some of the experiments regarding Hypothesis 2, namely those in which flesh still was plentiful after an initial consumption by lions. Nevertheless, this is the only criterion that makes the frequencies observed on the bones from the FLK Zinj site similar to such a set of experiments modeling secondary access to carcasses. If we notice the differential distribution of cut marks according to bone section, we can see that, as mentioned before, as many as $59 \%$ of the cut-marked specimens from meaty limbs of smaller animals and $73 \%$ of the cutmarked specimens from the same elements of larger animals occur on mid-shaft fragments (Bunn \& Kroll, 1986). Bearing in mind that Hypothesis 1 experiments yielded a mean frequency of cut-marked mid-shaft specimens higher than $50 \%$, the archaeological data seem to fit better this referential framework (Hypothesis 1) than the other (Hypothesis 2).
With respect to the cut-mark patterns according to bone type, the data drawn from the FLK Zinj site show (with respect to larger animals) a clear differential distribution: upper $(43 \%)$ and intermediate $(45 \%)$ limb bones make up most of the cut-marked specimens $(88 \%)$ versus metapodials $(12 \%)$. Proportionately (according to NISP) upper limbs show a greater representation of cutmarked specimens $(40 \%)$ than intermediate limb bones (30\%). This result is similar to the one obtained in Hypothesis 1 experiments.

However such comparison is somewhat incomplete. As I said before, the total percentage of cutmarked specimens on the bones from the FLK Zinj site shows a particular pattern. But this is due to the fact that in order to obtain them, Bunn \& Kroll (1986) only used the relationship between the sample of cut-marked bones subjected to microscopical identification and the total number of pieces of each skeletal part. Nonetheless, in the analysis that they carried out there is a large number of pieces with macroscopically identified cut marks, that were not used in the elaboration of their cut-mark patterns. Bunn \& Kroll (1986: 437) claimed that "...the remainder of the macro-sample specimens have not been studied microscopically" and Bunn (1981: 22) further acknowledged that "macroscopic examination and comparison with known types of grooves on modern bones is a sufficiently reliable basis for the identification of multiple sets of cut marks and most isolated cut marks on fossil bones". He randomly selected number of cut-marked bone specimens from a sample made up of specimens showing macroscopically identified cut marks, and observed that microscopic identification matched the macroscopic one in almost $90 \%$ of the cases (only 3 cases were doubtful and none negative). For this reason and backed up by personal experience, I will also use the macroscopically identified bone sample from Bunn \& Kroll's (1986) study to observe the new patterns that emerge.

The percentage of cut-marked bones with respect to NISP is $21,5 \%$ in smaller animals and $32 \%$ in larger animals. Cut-mark patterns are distributed preferentially on upper/intermediate limb bones (89\% in larger animals and $87 \%$ in smaller animals) with similar percentages to the Hypothesis 1 experiments: $44 \%$ on upper bones in larger animals, $31 \%$ in smaller animals; $45 \%$ in the intermediate bones in larger animals and $56 \%$ in smaller animals. If we obtain these percentages 
proportionally to cut-marked NISP per each element, this differential distribution becomes clearer. The cut-marked specimens from upper limb bones of larger animals are $57 \%$ of the total of cut-marked specimens from the meaty bones and intermediate bones represent only $43 \%$. Furthermore, $70 \%$ of the cut-marked specimens in larger animals and $51 \%$ in smaller animals occur on mid-shaft specimens. This makes this cut-mark pattern resemble those observed in Hypothesis 1 experiments.

All these patterns exhibited by the FLK Zinj site, whether based on the microscopically identified cut-marked specimens or on the mixed set of cut-marked bones (macroscopically and microscopically identified) are similar to those obtained in the experiments that simulated a primary access of hominids to carcasses. If we take into account that the most widespread form of lion behavior in other ecosystems is that observed in Maasai Mara and not Kulalu and that Blumenschine's hypothesis is based on a Serengeti-(Mara) pattern (Blumenschine, 1986: 139), the contrast between the Mara sample used in my experimentation and the results obtained in the FLK Zinj is very remarkable. Cut-mark percentages and distribution in upper/intermediate limb bones (especially in humerus and femur) cannot be accounted for in terms of a secondary access to carcasses. Although a behavior aimed at marrow extraction could also be reflected in the form of cut marks on lower limb bones -as skinning is necessary (Blumenschine, 1986)-, it would barely leave any mark on the other bones, and surely almost none on upper limb bones and their shafts.

However, the strength of these conclusions depends on whether the range of variation of the samples of both sets of experiments do not significantly overlap. The extent of the confidence one can put in the outcome of a hypothesis test depends very much on the statistical significance of the sample used. Small samples with a wide variation are more likely to show a given result by chance than wider samples with less variation. In order to test the statistical significance of a given sample, and therefore the likelihood that the future increasing in the sample will not make it vary in a significant way, the two-tailed confidence interval analysis will indicate how big the range of variation of a given mean figure is, by showing the expected limit above and below that number. In order to test a null-hypothesis or to differentiate between two sets of statistical assumptions, samples under analysis have to show no overlap in their ranges of variation. The shorter the range of variation of a sample, the more trustworthy it is. Limited ranges of variation and lack of overlap between different samples provide a reliable basis for testing opposite hypotheses and making statistical inferences.

If we observe table 3 and figure 2, we will notice that there is no overlap between the ratios of cut-marked specimens with respect to the total NISP of both samples. The sample of larger mammals at FLK Zinj site -and this is the size of animals for which these experiments were carried out- falls within the Hypothesis 1 range of variation. Smaller animals fall between the range of variation of both experimental samples.

Nonetheless, the most conclusive evidence for the validity of the interpretations advanced above is shown by the contrasting patterns of cut mark representation on upper limb bones. There is no overlap between the range of variation of Hypothesis $1(25 \%-87 \%)$ and Hypothesis $2(0 \%-15 \%)$ experiments when dealing with the Maasai Mara sample (Fig. 2). Both the smaller and larger mammals of FLK Zinj are situated within the range of variation of the former. Something similar could be said about the representation of cut marks on intermediate limb bones. Although a slight overlap between both samples exists (15\%-66\% in Hypothesis 1 and $0 \%-38 \%$ in Hypothesis 2), the larger mammals of FLK Zinj are found outside this overlapping zone and well represented in the Hypothesis 1 experimental sample. Lower limb bones are cut marked in similar rates in both experimental scenarios and in the FLK Zinj bone sample as would be expected from defleshed bones. Skinning, disarticulation and marrow extraction account for cut marks in all cases (see Fig. 2).

Another proof of difference between both samples is observed in the percentages of cut-marked mid-shafts. The ranges of variation between Hypothesis 1 experiments $(25 \%-74 \%)$ and Hypothesis 2 experiments $(0 \%-16 \%)$ do not overlap. The smaller and larger carcasses of FLK Zinj are outside the range of variation of Hypothesis 2 experiments and only the latter are included in that shown by Hypothesis 1 experiments.

These interpretations still hold if we lump together all the data of the complete three-patterned experiments made both in Maasai Mara and Kula- 


\begin{tabular}{|c|c|c|c|c|c|c|}
\hline \multicolumn{7}{|l|}{ HYPOTHESIS 1} \\
\hline & TOTAL & ULB & ILB & LLB & $\mathrm{M}-\mathrm{SH}$ & ENDS \\
\hline$n$. assemblages & 4 & 4 & 4 & 4 & 4 & 4 \\
\hline mean+/- S.D. & $45+/-12,1$ & $56,2+/-19,4$ & $40,7+/-16,1$ & $8,5+/-16,5$ & $49,6+/-19$ & $45,7+/-6,8$ \\
\hline 95\% C.I. & $(26-64)$ & $(25,4-87)$ & $(15,2-66,2)$ & $(0-34,7)$ & $(24,8-74,4)$ & $(34,9-56,5)$ \\
\hline \multicolumn{7}{|l|}{ HYPOTHESIS 2} \\
\hline & TOTAL & ULB & ILB & LLB & $\mathrm{M}-\mathrm{SH}$ & ENDS \\
\hline n. assemblages & 4 & 4 & 4 & 4 & 4 & 4 \\
\hline mean+/- S.D. & $12,2+/-8,4$ & $3,9+/-6,2$ & $17,2+/-23,6$ & $19,2+/-8$ & $7,7+/-9,1$ & $16+/-11,2$ \\
\hline 95\% C.I. & $(0-25,2)$ & $(0-13,5)$ & $(0-53,7)$ & $(6,8-31,6)$ & $(0-21,6)$ & $(0-33,3)$ \\
\hline \multicolumn{7}{|l|}{ FLK $22 \quad$ Zini } \\
\hline & TOTAL & ULB & ILB & LLB & $M-S H$ & ENDS \\
\hline micro $s$ & $15(51 / 33)$ & $18,6(22 / 118)$ & $13,8(23 / 166)$ & $10,9(6 / 5,5)$ & $13,6(35 / 256)$ & $19,2(16 / 83)$ \\
\hline micro I & $23(37 / 159)$ & $26(11 / 42)$ & $29,8(20 / 67)$ & $12(6 / 50)$ & $20(21 / 105)$ & $29,6(16 / 54)$ \\
\hline macro $\mathrm{S}$ & $21.5(73 / 339)$ & $27,1(32 / 118)$ & $19,8(33 / 166)$ & $16,3(9 / 55)$ & $20,3(52 / 256)$ & $25,3(21 / 83)$ \\
\hline macro L & $32(51 / 159)$ & $40(17 / 42)$ & $40,2(27 / 67)$ & $14(7 / 50)$ & $29,5(31 / 105)$ & $37(20 / 54)$ \\
\hline
\end{tabular}

Tab. 2. Mean percentages of cut-marked specimens in relation to the total number of specimens from upper (ULB), intermediate (ILB), lower (LLB) limb bones, mid-shafts (MSH) and ends for the experiments of the Hypotheses 1 and 2 and the FLK Zinj site. Results for the Hypothesis 2 are for the Maasai Mara \& Kulalu samples together. $\mathrm{s}=$ FLK smaller mammals (micro); $\mathrm{S}=$ FLK smaller mammals (macro); 1 = FLK larger mammals (micro); $\mathrm{L}=$ FLK larger mammals (macro). Analysis of $95 \% \mathrm{C}$. I. for both sets of experiments are included. They were calculated using the $t$ distribution, where $\mathrm{t}_{0.025}$ is the critical value of $\mathrm{t}$ with $\mathrm{n}-1$ degrees of freedom.

lu (Fig. 3; Tables $2 \&$ 3). Although this profile is not realistic, as it embodies the results of having secondary access to carcasses abandoned by lions with different proccessing behaviors, it still can be used to compare different degrees of variation in this sample with those exhibited by the Hypothesis 1 experiments. If we look at tables $2 \& 3$ and figure 3 , we can notice that the overlap between the ranges of variation of both samples is minimal in the total percentage of cut-marked specimens. The larger mammals of FLK Zinj are situated in the Hypothesis 1 sample. The situation is the same as in the Maasai Mara sample. On upper limb bones there is no overlap, with Hypothesis 1 (25\%-87\%) well differentiated from Hypothesis $2(0 \%-13 \%)$. On intermediate limb bones the situation becomes a little more ambiguous. The ranges of variation between the Hypothesis 1 experimental scenario (15\%-66\%) and the Hypothesis 2 sample $(0 \%-53 \%)$ are very similar. Never-

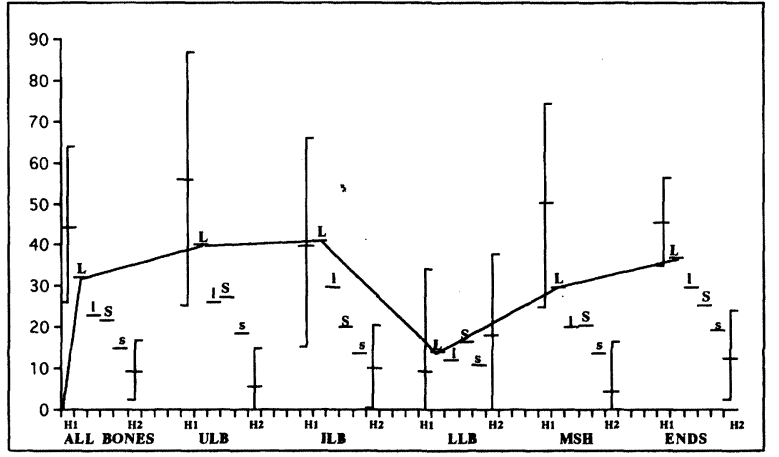

Fig. 2. Range of variation of the Hypothesis 1 \& 2 experiments. Data from the Hypothesis 2 experiments come solely from the Maasai Mara sample. For the FLK Zinj site: $s=$ FLK smaller mammals (micro); $\mathrm{S}=$ FLK smaller mammals (macro); 1=FLK larger mammals (micro); $\mathrm{L}=\mathrm{FLK}$ larger mammals (macro). See comment in text. 


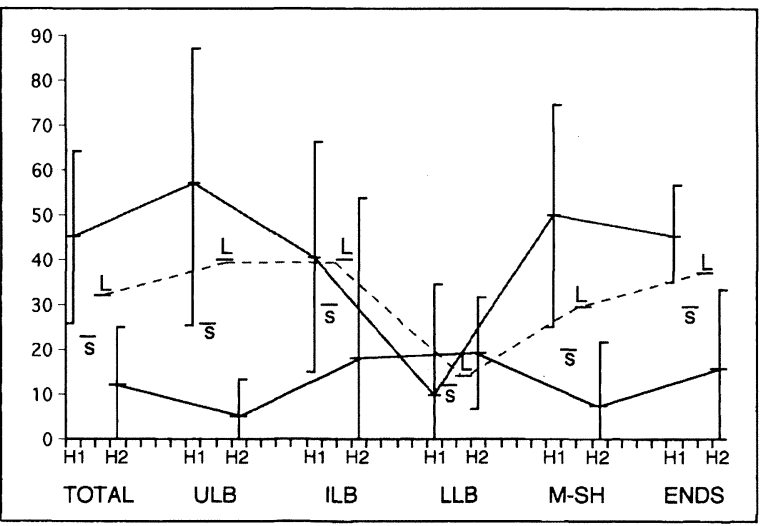

Fig. 3. Range of variation of the Hypothesis 1 \& 2 experiments. Data for the Hypothesis 2 experiments come from the Maasai Mara and Kulalu samples. Data from smaller (S) and larger animals (L) from the FLK Zinj site are also shown. The range of variation of upper limb bone specimens showing cut marks for both experimental samples does not overlap. See comment in text.

theless, when comparing the frequencies of cutmarked mid-shafts, no overlap exist between the experimental samples and the data drawn from FLK Zinj. Hypothesis 1 experiments (25\%$74 \%$ ) are much closer to the archaeological sample than Hypothesis 2 experiments (0\%-21\%). Larger mammals in the FLK Zinj appear in the range of variation of the Hypothesis 1 sample.

Therefore, the most remarkable differences when comparing the Hypothesis 1 sample to the Hypothesis 2 experimental model are observed on the upper limb bones and the mid-shaft sections (Fig. 3). However, when the Hypothesis 2 model incorporates the data from only the Maasai Mara sample, a further difference can be noticed on intermediate limb bones (Fig. 2). Both smaller and larger mammals from the FLK Zinj are well represented outside the range of variation of Hypothesis 2 and inside the Hypothesis 1 sample. In general, if we observe the pattern in Figure 3, the fauna from the FLK Zinj, especially regarding larger animals, is very similar to the Hypothesis 1 experimental scenario, and remarkably contrary to the Hypothesis 2 pattern. This resemblance suggests that a behavior similar to that modeled in Hypothesis1 experiments was the responsible for the cut mark pattern observed at the FLK Zinj site.

This situation further confirms the statements made by Domínguez-Rodrigo (in press) about hominid involvement with fleshed carcasses at sites.

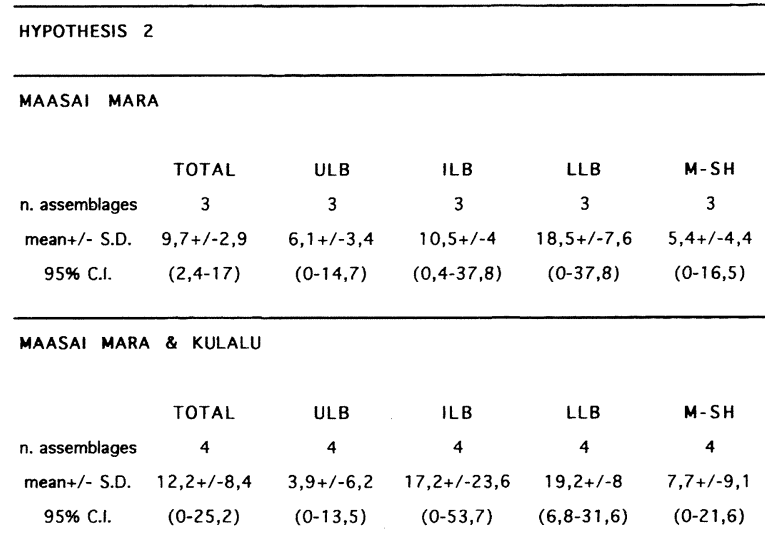

Tab. 3. Mean percentages of cut-marked specimens to the total number of specimens from upper (ULB), intermediate (ILB), lower (LLB) limb bones, mid-shafts (MSH) and ends for the experiments of the Hypothesis 2 and the FLK Zinj site. Results for the Maasai Mara Sample and for the Maasai Mara \& Kulalu sample are shown separately. $\mathrm{s}=$ FLK smaller mammals (micro); $\mathrm{S}=$ FLK smaller mammals (macro); I = FLK larger mammals (micro); L = FLK larger mammals (macro). Analysis of $95 \%$ C.I. for both sets of experiments are included. They were calculated using the $\mathrm{t}$ distribution, where $\mathrm{t}_{0.025}$ is the critical value of $t$ with $n-1$ degrees of freedom.

These results contradict Selvaggio's (1994) interpretations of the cut mark patterns of the FLK Zinj site. Despite differences in interpretation, she acknowledged that "limbs were abandoned by lions with little or no flesh on humeri and femora. Ocassionally the skin was not completely consumed from the tibiae or the radius-ulnae and small scraps of flesh remained near the distal epiphyses" (Selvaggio, 1994: 54-55). She further claimed that "long bones abandoned by large groups of carnivores were usually disarticulated from the carcass and while the marrow cavity remained intact, the bones were usually encountered completely defleshed" (Selvaggio, 1994:124).

Therefore, both studies (Selvaggio's and mine) lead to the same conclusion with respect to carcasses processed by lions. Upper limb bones are utterly defleshed on most of the ocassions. According to her, this observation could also be extended to other predators and smaller carcasses: "rarely were scraps of flesh available on proximal long bones abandoned by carnivores in the Carnivore-Hóminid sample" (Selvaggio, 1994: 122).

So, it is not surprising that in her experimental 
sample, also less than $5 \%$ of mid-shafts showed any mark (Selvaggio, 1994).

\section{CONCLUSIONS}

The predominance of cut-marked specimens from upper limb bones and mid-shafts on the larger mammal sample of FLK Zinj, with a similar distribution to that observed in the Hypothesis 1 experimental sample, indicates that hominids were manipulating fleshed carcasses. This is consistent with hunting, confrontational scavenging (Bunn \& Kroll, 1986, 1988: Bunn \& Ezzo, 1993) and passive scavenging from carcasses found dead, without the intervention of other carnivores (Capaldo \& Peters, 1995). It does not support Blumenschine's hypothesis that carcasses were obtained from felid kills, after they had fed on them, in a secondary access by hominids.

This study has also shown that cut mark patterns are indicative of the differential distribution of flesh, as predicted by Bunn \& Kroll (1986, 1988). Therefore, hominids were having primary access to intact carcasses. Taking this fact into account, the range of strategies of carcass obtainment are very limited. Passive scavenging from carnivore's kills is refuted by this study. The fact that undisturbed carcasses found dead is a rare phenomenon would also exclude this type of strategy as an option. Carcasses that die from natural causes (drought, mass drowning, and aging) are very scarce in time and space. Drought is confined to once every few years, drowning is spatially restricted to particular spots in ecological settings with migratory biomass. Aging is rare, since several predators show special incidence in the capture of old and young individuals (attritional age profiles). All those circumstances make early access to undisturbed carcasses almost anecdotical, despite its feasibility.

On the other hand, confronting predators to chase them away from their kills is a highly speculative alternative. Although some modern human populations ocassionally confront carnivores to get access to their kills, they are equipped with modern gear (metal implements) that makes them inappropriate proxies for Plio-Pleistocene hominids. This strategy, despite its likeliness, involves a highly costly and risky behavior that makes hunting a more effective means of obtaining carcasses. Nonetheless, given the fact that primary access to carcasses seems to be supported by this set of studies, future research should shed more light about the strategies that hominids used to obtain their animal resources.

\section{ACKNOWLEDGEMENTS}

I would like to thank the K.W.S. (Kenyan Wildlife Service), the A.D.C. (Agricultural Development Corporation), the Office of the President of Kenya, and especially Mr. Gishangi, Director of K.W.S. at Tsavo East National Park, for their permits and help in field research. I would also like to thank the Olchorro le Musiara rangers and acknowledge the aid that I received from Raquel Martí and John J. Anière during my stay in Maasai Mara and Kulalu \& Galana respectively. Special thanks are for Peter, Nguyu, Abadiba and Selelo, my efficient field butchers. This research was funded by the "Projectes per Africa" Foundation, and a Competitive Grant from the Complutense University. I appreciate the comments made by S. Semaw and A. Gilman on a earlier draft of this paper.

\section{REFERENCES}

BINFORD, L.R. (1981): Bones: ancient men, modern myths. Academic Press. New York.

- (1985): "Human ancestors: changing views of their behavior". Journal of Anthropological Archaeology, 4: 292-327.

- (1988): "Fact and fiction about the Zinjanthropus Floor: Data, arguments and interpretations". Current Anthropology, 29: 123-135.

BLUMENSCHINE, R.J. (1986): Early hominid scavenging opportunities. Implications of carcass availability in the Serengeti and Ngorongoro ecosystems. B.A.R. International Series, 283. Oxford.

- (1988): "An experimental model of the timing of hominid and carnivore influence on archaeological bone assemblages". Journal of Archaeological Science, 15: 483-502.

- (1991): "Hominid carnivory and foraging strategies, and the socio-economic function of early archaeological sites". Philosophical Transactions of the Royal Society of London, 334: 211-221.

- (1995): "Percussion marks, tooth marks and the experimental determinations of the timing of hominid and carnivore access to long bones at FLK Zinjanthropus, Olduvai Gorge, Tanzania". Journal of Human Evolution, 29: 21-51.

Blumenschine, R.J. \& Bunn, H.T. (1987): “On theoretical

T. P., 54, n. $^{\circ} 2,1997$ 
framework and tests of early hominid meat and marrow adquisition. A reply to Shipman". American Anthropologist, 89: 444-447.

Blumenschine, R.J.; Cavallo, J.A. \& Capaldo, S.D. (1994): "Competition for carcasses and early hominid behavioral ecology: a case study and a conceptual framework". Journal of Human Evolution, 27: 197-213.

Blumenschine, R.J. \& Madrigal, T.C. (1993): "Long bone marrow yields of some African ungulates". $\mathrm{Jo}$ urnal of Archaeological Science, 20: 555-587.

Blumenschine, R.J. \& Marean, C.W. (1993): “A carnivore's view of archaeological bone assemblages". In J. Hudson (ed.): From bones to behavior: Ethnoarchaeological and experimental contributions to the interpretations of faunal remains. Southern Illinois University, Illinois: 273-300.

Blumenschine, R.J. \& Selvaggio, M.M. (1988): "Percussion marks on bone surfaces as a new diagnostic of hominid behavior". Nature, 333: 763-765.

BunN, H.T. (1981): "Archaeological evidence for meateating by Plio-Pleistocene hominids from Koobi Fora, Kenya". Nature, 291: 574-577.

- (1982): Meat-eating and human evolution: studies on the diet and subsistence patterns of Plio-Pleistocene hominids in East Africa. Ph. Dissertation. University of California. Berkeley.

- (1983): "Evidence on the diet and subsistence patterns of Plio-Pleistocene hominids at Koobi Fora, Kenya, and at Olduvai Gorge, Tanzania". In J. Clutton-Brock (ed.): Animals and Archaeology: Hunters and their Prey . B.A.R. International Series, 163. Oxford: $21-$ 30.

- (1991): "A taphonomic perspective on the archaeology of human origins". Annual Review of Anthropology, 20: 433-467.

BunN, H.T. \& Ezzo, J.A. (1993): "Hunting and scavenging by Plio-Pleistocene hominids: nutritional constraints, archaeological patterns, and behavioural implications". Journal of Archaeological Science, 20: 365-398.

BunN, H.T. \& Kroll, E.M. (1986): "Systematic butchery by Plio-Pleistocene hominids at Olduvai Gorge, Tanzania". Current Anthropology, 27: 431-452.

CAPALDO, S.D. (1995): Inferring hominid and carnivore behavior from dual-patterned archaeological assemblages. Ph. D. Thesis. Rutgers University, New Brunswick.

Capaldo, S.D. \& Peters, C.R. (1995): “Skeletal inventories from wildebeest drownings at Lakes Masek and Ndutu in the Serengeti ecosystem of Tanzania". Journal of Archaeological Science, 22: 385-408.

Cavallo, J.A. (1993): "Through field glasses darkly: a reassessment of FLK Zinjanthropus as an early hominid "living site' or "central place". Paper presented at Four Million Years of Hominid Evolution in Africa. International Congress in honour of Dr. M.D.
Leakey's outstanding contribution in Paleoanthropology. Arusha, 1993, Tanzania. Dartmart, Germany.

Domínguez-Rodrigo, M. ( in press): "Testing meat-eating in early hominids: an analysis of butchery marks on defleshed carcasses". Actas del Congreso Internacional de Paleontología de Orce, Granada, 1996.

- (in press): "Meat-eating by early hominids at the FLK Zinj site, Olduvai Gorge, Tanzania: an experimental approach using cut mark data". Journal of Human Evolution.

Domínguez-Rodrigo, M. \& Martí, R. (1996): “Un estudio etnoarqueológico de un campamento temporal Ndorobo (Maasai) en Kulalu (Kenia)". Trabajos de Prehistoria, 53 (22): 131-143.

Haynes, G. (1991): Mammoths, Mastodonts and Elephants. Cambridge University Press. Cambridge.

IsAAC, G.L. (1983): "Bones in contention: competing explanations for the juxtaposition of Early Pleistocene artifacts and faunal remains". In J. Clutton-Brock and C. Grigson (eds.): Animals and Archaeology 1. Hunters and their prey. B.A.R. International Series, 163. Oxford: 3-19.

- (1984): "The archaeology of human origins: studies of Lower Pleistocene in East Africa, 1971-1981". Advances in World Archaeology, 3: 1-87.

KeELEy, L.H. \& Toth, N. (1981): "Microwear polishes on early stone tools from Koobi Fora, Kenya". Nature, 293: 464-465.

Marean, C.W. \& Ehrhardt, C.L. (1995): "Paleoanthropological and paleoecological implications of the taphonomy of a sabertooth's den". Journal of Human Evolution, 29: 515-547.

Marean, C.W., SPencer, L.M., Blumenschine, R.J. \& CAPALDO, S. (1992): "Captive hyaena bone choice and destruction, the Schlepp effect and Olduvai archaeofaunas". Journal of Archaeological Science, 19: 101-121.

PotTs, R. (1982): Lower Pleistocene Site Formation and Hominid Activities at Olduvai Gorge, Tanzania. Ph. Dissertation. Harvard University, Massachussets.

- (1988): Early hominid activities at Olduvai. Aldine. New York.

PotTs, R. \& Shipman, P. (1981): "Cutmarks made by stone tools from Olduvai Gorge, Tanzania”. Nature, 291: 577-580.

SelvagGio, M.M. (1994): "Carnivore tooth marks and stone tool butchery marks on scavenged bones: archaeological implications". Journal of Human Evolution, 27: $215-228$.

Shipman, P. (1986): "Scavenging or hunting in early hominids: theoretical frameworks and tests". American Anthropologist, 88: 27-43.

Tilson, R.L. \& Henschel, J.R. (1986): "Spatial arrangement of spotted hyena groups in a desert environment, Namibia”. African Journal of Ecology, 24: 173180.

T. P., 54, n. $^{\circ} 2,1997$ 